\title{
Comparison of Dye Extraction or Dye Penetration Methods to Quantitatively Determine Microleakage of Three Different Root Canal Sealers
}

\section{Sadullah KAYA ${ }^{1 *}$, Senem YIGIT OZER ${ }^{1}$, İzet YAVUZ ${ }^{2}$ and Haluk AYDIN ${ }^{3}$}

${ }^{1}$ Dicle University, Dental Faculty, Department of Endodontics, Diyarbakir, Turkey

${ }^{2}$ Dicle University, Dental Faculty, Department of Pediatrics Dentistry, Diyarbakir, Turkey

${ }^{3}$ Dicle University, Science and Arts Faculty, Department of Chemistry, Diyarbakir, Turkey

\begin{abstract}
Aim: This study investigated the feasibility of an approach to determine the volume of dye penetration using methlene blue as dye in comparison to a well known dye extraction method.

Materials and methods: One hundred and fifty teeth were randomly divided into two groups (dye extraction or dye penetration methods) of 75 teeth. After, 75 teeth were divided into 3 subgroups for three different root canal sealers. For the volumetric analysis of dye penetration method area of penetration was converted into volume and quantitative analysis was performed. For the dye extraction method dye concentration in the solution was analyzed using an UV-spectrophotometer. In both techniques roots were evacuated prior to dye introduction to prevent air entrapments providing reliable results. The sealabilities of the root canal sealers Ketac-Endo, MetaSEAL, and AH Plus JET were evaluated and results were compared regarding dye extraction or dye penetration methods. Furhermore, 36 teeth were used as positive and negative controls.
\end{abstract}

Results: Dye extraction and volume measurement of dye penetration methods showed that Ketac-Endo displayed the highest apical leakage, followed by MetaSEAL $(P<0.05)$. Correlation of the results obtained with these two different evaluation methods showed that there was no statistical difference between dye extraction and dye penetration methods $(P>0.05)$

Conclusions: This study showed that results of volumetric determination of dye penetration method were not different when compared with the results of dye extraction method with vacuuming. In simplifing the procedures, dye extraction method may be preferred.

Keywords: Dye penetration; Methlene blue; Quantitative; Vacuuming, Volume

\section{Introduction}

Up to date, studies have evaluated the outcomes of different root canal sealers with various leakage models [1-4]. The major problem of most laboratory-based leakage testing models was that the obtained data was qualitative rather than being quantitative, raising doubts about reliability [1-3]. However dye extraction methods are reported to give quantitative results [4]

Dye extraction studies use dye penetration and samples stained using $2 \%$ methlene blue are stored in a hermetically sealed vial containing nitric acid with a concentration of $65 \%$ for three days. The vials are centrifugated at high speed to separate gutta-percha debris from the extracted dye. The supernatant from each sample is then analyzed in an UV-visible spectrophotometer with concentrated nitric acid as the blank $[1,5,6]$. Although this method gives quantitative results, it may have some weaknesses: the sensitivity of detecting differences among the filling techniques may be low [5], dye absorbed from the unprotected apical dentin may affect the results [1], and, more importantly, because the color of the samples has never been qualified, the possibility of it affecting the spectrophotometer readings is overlooked in all studies.

One of the major problems in which dyes are used for penetration is the entrapped air in voids along root canal fillings [7,8]. Spångberg [8] and Goldmen [9] have reported that entrapped air can inhibit dye penetration which results in the failure to demonstrate preformed voids. They reported that using a vacuum technique completely penetrates dye in all samples. Oliver and Abbott [7] also evaluated the effect of entrapped air on the ability of methlene blue dye and reported the vacuum method to be the most reliable method for dye penetration studies.

An improved form of the dye extraction technique determines the penetrated dye volumetrically, which is a method commonly used in biochemistry for the quantitative analysis of materials adsorbing light via spectrophotometry [10-13]. In this technique, methlene blue, which has a known molecular weight $\left(\mathrm{M}_{\mathrm{A}}=319.868 \mathrm{~g} \cdot \mathrm{mol}^{-1}\right)$, wavelength $(662 \mathrm{~nm})$, color index (52015), and surface area $\left(\sigma=120 \mathrm{~A}^{0.2}\right)$, is used as the adsorbent. Adsorption is the process by which chemicals are held on the surface of a mineral or soil particle, and the volume of the chemicals can be calculated using this parameter. It is totally different from absorption, which is the process of one substance entering into the inner structure of another $[12,14]$.

In this technique, briefly, after vacuuming and staining the teeth with dye, methlene blue penetrates the gaps, indicating leakage. It is isolated by several biochemical procedures, and the surface area

*Corresponding author: Sadullah KAYA, Dicle University, Dental Faculty Department of Endodontics, 21280 Diyarbakir, Turkey, GSM: 905326311490 E-mail: sadullahkaya@hotmail.com

Received July 08, 2011; Accepted October 10, 2011; Published October 20, 2011

Citation: KAYA S, OZER SY, YAVUZ I, AYDIN H (2011) Comparison of Dye Extraction or Dye Penetration Methods to Quantitatively Determine Microleakage of Three Different Root Canal Sealers. Dentistry 1:105. doi:10.4172/2161 1122.1000105

Copyright: ( ) KAYA S, et al. This is an open-access article distributed under the terms of the Creative Commons Attribution License, which permits unrestricted use, distribution, and reproduction in any medium, provided the original author and source are credited. 
of the adsorbed dye is exactly calculated using varying formulas. The surface area is converted into volume, and the penetrated dye is calculated volumetrically. Because data are not only acquired using a spectrophotometer, the varying colors of decalcified samples are not a problem in this method.

Thus, the purpose of this study was to adapt this technique into a microleakage assay using three different-based root canal sealers, and in which the dye extraction method was served as the control. The null hypothesis is that there is difference between the volume determination of dye penetration and dye extraction methods.

\section{Material and Methods}

\section{Specimen preparation}

One hundred and eighty six single-rooted extracted human mandibular premolars were stored in distilled water at $4^{\circ} \mathrm{C}$ until use. The crowns were removed at the enamel-dentin junction with a diamond disk under water cooling. A \#10 K-file was introduced into the canal to radiographically measure the working length and to check the patency of the apex. The root canals were prepared with ProTaper Universal (Dentsply Maillefer, Ballaigues, Switzerland) to an ISO \#30, using a \#10 K-file between the rotary files to verify the apex patency. $2.5 \% \mathrm{NaOCl}$ was used as an irrigant between each file. The final rinse was performed using $3 \mathrm{~mL}$ of $2.5 \% \mathrm{NaOCl}$ and $17 \%$ EDTA, followed by $3 \mathrm{~mL}$ of distilled water. Then, the root canals were dried using paper points.

Of the teeth, 36 served as negative $(n=18)$ and positive controls $(n=18)$; the negative controls were completely covered with three layers of varnish, and the positive controls were enlarged, but not root filled. The remaining 150 teeth were then randomly divided into three groups of 50 teeth each, to be filled with 0.04 tapered gutta-percha (DiaDent Group Int., Canada) and cold lateral compaction using one of three sealers. In Group 1, Ketac-Endo (3M ESPE, Seefeld, Germany) glass-ionomer based paste was mixed according to manufacturer's information. In Group 2, MetaSeal (Parkell Inc, Farmington, NY) methacrylate resin-based sealer was hand-mixed using one scoop of powder and three drops of liquid for $30 \mathrm{~s}$. In Group 3, AH Plus Jet (Dentsply Caulk, Milford, DE) epoxy resin-based components A and $\mathrm{B}$ were mixed using an automixing syringe. Excess gutta-percha was removed from the coronal cavity up to the level of the cementoenamel junction with a hot instrument (15), and root canal orifices were sealed using a flowable resin composite (Versite Flow, Kerr Corp., CA, US). Only MetaSeal samples were light-cured for $40 \mathrm{~s}$ after excess guttapercha removal.

After root canal obturation, teeth were stored for $24 \mathrm{~h}$ at $37^{\circ} \mathrm{C}$ and $100 \%$ humidity in an incubator to allow setting of the sealer.

Samples for the dye extraction method $(n=75)$ were convered with nail varnish, with the exception of the apical $0.5 \mathrm{~mm}$, and setting of the varnish was completed before dipping into methlene blue. The teeth were then placed in vacuum chambers (five chambers each containing 15 samples, Edwards E306, Severn Sciences, Bristol, UK) containing $2 \%$ methlene blue and a vacuum of $7.98 \mathrm{~Pa}$ for $15 \mathrm{~min}$ was applied.

Samples for volumetric evaluation $(n=75$, each experimental group consisted 25 teeth) were covered with three layers of varnish, with the exception of the apical $0.5 \mathrm{~mm}$. Laquer was applied on a \#15 finger-spreader (Mani Inc., Tocigi-Ken, JA), which was inserted from the apical portion $0.5 \mathrm{~mm}$ and fixed with nail varnish. After the total set of nail varnish, the finger-spreader was gently removed, keeping the apical portion open and standard for all samples. Then they were placed in vacuum chambers (five chambers each containing 15 samples, Edwards E306, Severn Sciences, Bristol, UK) containing 2\% methlene blue and a vacuum of 7.98 $\mathrm{Pa}$ for $15 \mathrm{~min}$ was applied [16].

After removal from the dye, the teeth were rinsed under tap water for $30 \mathrm{~min}$, and all residues of methlene blue and varnish were removed with a Parker blade \#15 and polishing discs.

\section{Dye extraction method}

Stained teeth from three groups $(n=75)$ were stored in a hermetic sealed vial containing $65 \%$ nitric acid for three days. The vials were then centrifugated at $14,000 \mathrm{rpm}$ for $5 \mathrm{~min}$ to separate gutta-percha debris from the extracted dye. Dye concentration in the supernatant solution was analyzed using an UV-spectrophotometer (Shimadzu UV-160, Shimadzu Corp., Kyoto, Japan) at $550 \mathrm{~nm}$ using concentrated nitric acid as a blank.

\section{Volumetric evaluation of dye penetration}

Samples $(n=75)$ were placed into three different glass vials containing $65 \%$ nitric acid until they all dissolved completely approximately for 72 -h. At the end of the adsorption period, the solution was centrifugated for $5 \mathrm{~min}$ at $14,000 \mathrm{rpm}$. After centrifugation, the dye concentration in the supernatant solutions was analyzed using an UV-spectrophotometer (Shimadzu UV-160, Shimadzu Corp., Kyoto, Japan) by monitoring the absorbance.

\section{Biochemical procedures for volumetric evaluation of dye penetration}

The stock solution of methlene blue (Merck Chemical, Istanbul Turkey) was prepared with $4.75 \mathrm{~g} / \mathrm{L}$ of dye with a $\mathrm{pH}$ of 6.98 , buffering with $\mathrm{H}_{2} \mathrm{PO}_{4}^{-/} / \mathrm{HPO}_{4}^{2-}$ in $1000 \mathrm{mg} / \mathrm{L} .100 \mu \mathrm{L}$ of this solution was placed on the spectrophotometer, and the maximum absorption wavelength $\left(\lambda_{\max }\right)$ was determined at $662 \mathrm{~nm}$. A series of diluted solutions was prepared with the same MB stock using $100 \mathrm{~mL}$ of distilled water in each beaker to dilute the $2 \% \mathrm{MB} .20 \mathrm{~mL}$ of increments were added to the solution to obtain varying concentrations [14]. The absorption wavelengths for different concentrations of methlene blue were measured to construct the calibration graph (Figure 1). With the help of the calibration graph, when the spectrophotometrically obtained absorption values were used, total concentrations were calculated by means of the equation $\mathrm{A}=(0.205 . \mathrm{C})-0.0139$.

Concentration values were converted into volumetric values in $\mathrm{mm}^{3}$ using the mass and density values that were obtained via the calibration graph. Following the use of the equation $S=V_{M} / M_{A} \cdot \sigma \cdot N_{A^{\prime}}$

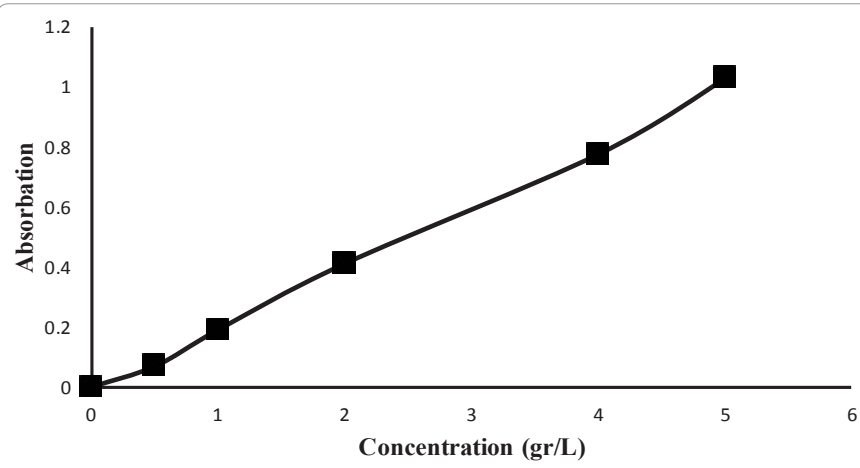

Figure 1: Calibration curve of methylene blue in different concentration. 
where $S$ is surface area, $V_{M}$ is the single incremental capacity, $M_{A}$ is the molecular weight, $\sigma$ is the surface area of a single adsorbed particle, and $\mathrm{N}_{\mathrm{A}}$ is the Avogado constant, [16] surface area is calculated.

\section{Statistical analysis}

The results were evaluated statistically using one-way analysis of variance (ANOVA) at 5\% significance levels with the Tukey HSD test for multiple comparison post hoc tests. The analysis of correlation (Pearson test) was performed for the comparison of methods.

\section{Results}

\section{Dye extraction method}

The results of the dye extraction test are shown in Table 1 . The mean absorbance values were 620, 410, and 213 for the Ketac-Endo, MetaSeal, and AH Plus JET, respectively. A one-way ANOVA showed a statistical difference among the sealers $(\mathrm{P}<0.05)$.

The positive control showed total dye absorbance, of 5000. Negative control samples had a low absorbance of 62 , close to that of the blank (nitric acid), which had absorbance of $52(\mathrm{P}>0.05)$ due to the color of the samples. Evaluating the leakage methods, results showed no statistical difference between the groups $(\mathrm{P}>0.05)$.

\section{Volumetric determination of leakage method}

Microleakage results in $\mathrm{mm}^{3}$ are given in Table 1 . The mean volumes of apical leakage values were $7.20 \times 10^{-4} \mathrm{~mm}^{3}$ for Ketac-Endo, $5.25 \times 10^{-4} \mathrm{~mm}^{3}$ for MetaSeal, and $4.52 \times 10^{-4} \mathrm{~mm}^{3}$ for AH Plus JET. A significant statistically difference in leakage volume was found between the groups $(\mathrm{P}<0.05)$. The positive controls demonstrated high apical microleakage (mean: $28 \times 10^{-4} \mathrm{~mm}^{3} ; \mathrm{P}<0.001$ ), while no leakage was detected in the negative control group.

\section{Discussion}

Creating an effective sealing in the root canal is very challenging. In recent years, obturating materials and sealers, such as glass ionomer, epoxy and methacrylate-based sealers, have been developed on the basis of dentin adhesion to seal the root canal more effectively [4]. A review article by Schwartz [17] pointed out the difficulties associated with sealing.

To date, studies have evaluated the outcomes of different root canal sealers with various leakage models [1-4]. The lack of specific $\mathrm{ADA}$ guidelines for adhesion tests with root canal sealers led to the development of a wide array of experimental models without standardization [18]. Different results were obtained, even though the materials tested were chemically similar to each other. As noted in the review by Kim [4] some studies have reported that methacrylate resinbased sealers perform better than epoxy resins; others have reported worse or equal results. This inconsistency may be due to the variations among the evaluation methods.

\begin{tabular}{|l|c|c|c|}
\hline Groups & No. teeth & $\begin{array}{c}\text { Volume measurement }\left(\mathrm{mm}^{3} .10^{-4}\right) \\
\text { Mean } \pm \text { SD }\end{array}$ & $\begin{array}{c}\text { Dye extraction } \\
\text { (Absorbance) } \\
\text { Mean } \pm \text { SD }\end{array}$ \\
\hline Ketac-Endo & 25 & $7.20 \pm 0.5^{\mathrm{a}}$ & $610 \pm 0.63^{\mathrm{a}}$ \\
\hline MetaSEAL & 25 & $5.25 \pm 0.5^{\mathrm{b}}$ & $410 \pm 1.14^{\mathrm{b}}$ \\
\hline AH Plus JET & 25 & $4.52 \pm 0.4^{\mathrm{c}}$ & $213 \pm 0.87^{\mathrm{c}}$ \\
\hline
\end{tabular}

a,b,c Groups with significant differences are shown with supercripted letters.

Table 1: Evaluation of dye penetration using volumetric determination of dye penetration method and dye extraction method.
Bacterial leakage studies are more reliable tests than those with dye but they do not simulate the conditions in the oral cavity, require long periods of observation time, and are labor-intensive De-Deus [5] evaluated the sensitivity and sealability of dye extraction and bacterial leakage techniques. They concluded that both techniques could be of too low sensitivity to detect differences between the filling techniques, and that the differences among the specimens might have been too small to detect.

On the other hand, the dye extraction method provides more reliable results than dye penetration because it measures all dye taken up in the root quantatively [19]. However, this technique also presents some drawbacks that should be taken into account and limited in future studies. First, the apical millimiter of the apex exposed to methlene blue is not covered with varnish, which permits dye to penetrate the apical dentin that is stained even after washing the samples under running water. The amount of methlene blue penetrating this space may reduce standardization and have negative and confusing outcomes affecting the results [1]. To eliminate these bias, in the volumetric dye penetration method, a 15\# finger-spreader was covered with laquer and inserted from the apical foramen $0.5 \mathrm{~mm}$; the sample was covered with three layers of nail varnish in this position. After complete setting of the nail varnish, the finger-spreader was gently removed without damaging the hollow space, making this opening the same standard size for all samples. Pilot studies were performed to determine the spreader size and length to be used to give the optimum apical opening. As previously reported by Roda \& Gutmann [20], clinically irrelevant internal air voids expand when the tooth is placed in vacuum conditions creating a seemingly significant, but artificial space for ink penetration; thus minimizing the uncovered tooth surface to $0.5 \mathrm{~mm}$ decreases this artificial space for ink penetration. Therefore more consistent results can be regarded by eliminating the uncertainty of entrapped air.

Secondly, the sample color may have caused small differences for the absorbance values detected using the spectrophotometer for the dye extraction method [6] because there may be vast differences in the color of samples; this issue has been overlooked until now. This difference was highlighted by Hashem [6] who explained the possible factors having an impact on their results for negative controls. In our study, because spectrophotometric readings were only a step in, but not the determinating factor of, the evaluation, our results have the advantage of not being solely affected by this issue. Thirdly, the methlene blue dye can be significantly decoloured by some dental filling materials like amalgam, Cavit or $\mathrm{ZnOE}$ because they contain reducing agents, such as $\mathrm{Ag}, \mathrm{Zn}, \mathrm{Cu}$, etc. which may change the chemical properties of the dye [21]. Also, formalin, which have been often used to store human teeth is reported to have possible effect on increasing the optical density of methlene blue [21]. Due to this possibility, in the present study, extracted teeth were kept in distilled water until use.

Based on these critical factors, a standardized, reliable, and reproducible method is a crucial requirement, which directed us to a new leakage model previously described $[10,11,13]$. The advantages of the dye extraction model are taken into account by staining the possible gaps between the root canal dentin and sealer using methlene blue with a vacuuming technique prior to staining. Dye is considered a more sensitive tracer than bacterial or bacteria-sized tracers $[3,22]$. The chemical adsorption phenomenon made it possible to volumetrically calculate the exact amount of dye absorbed due to leakage despite the evaluated quantities being very small [12], reducing the margin of error that may appear in other leakage techniques. In a dye penetration study by Vassiliadis [10] the volume of dye penetrating the root fillings was 
measured after dissolving the root in $5 \mathrm{ml}$ of $35 \% \mathrm{HNO}_{3}$. They found that dye was decoloured after $48 \mathrm{~h}$ and therefore decided to dissolve the roots for $24 \mathrm{~h}$ to keep the dye blue. But sample number used in this study was increased to 75 providing the methlene blue volume to increase and calculate the volume more precisely. Therefore, future studies concerning to use this volumetric approach with dye extraction should keep samples bigger in numbers which also increases the low sensitivity as was reported to be a disadvantage by De-Deus [5].

Our study results showed statistically significant differences between the groups $(\mathrm{P}<0.05)$ for both leakage methods (Table 1$)$. Ketac-Endo had, volumetrically, the highest leakage and poor sealing results, resembling previous leakage studies performed using different microleakage methods. The glass ionomer sealer is known to bond to dentin but may also bond to gutta-percha, because the polycarboxylic acid of the glass ionomer may react with the zinc component of guttapercha in a manner similar to the polycarboxylate cements that have already been used as endodontic sealers [23]. Lee [24] stated that Ketac-Endo gutta-percha bonds were only $20 \%$ of the dentin bonds suggesting that the potential for chemical reactions was limited which may have influenced the results and increased leakage. Kaplan [25] reported that Ketac-Endo sealer presented higher disintegration when in contact with humidity before its complete setting time. During the setting time of glass ionomer cements, the presence of humidity may cause dissolution of anions and cations which form the matrix creating voids through the cement [26], however it is difficult to protect KetacEndo cement from water contamination during its application in root canals because of periapical tissues.

According to our results MetaSeal performed better than KetacEndo; however, it leaked more than AH Plus JET $(\mathrm{P}<0.05)$. Probably AH Plus JET had greater adhesion to the root dentin than did MetaSEALand Ketac-Endo. This may be related to the fact that, as an epoxy resin-based sealer, AH Plus JET has better penetration into microirregularities due to its creep capacity and long setting time, which increases the mechanical interlocking previously reported by Nunes [18]. As stated on the manufacturers's safety data sheets, AH Plus JET [27] has a slower setting $\left(37^{\circ} \mathrm{C}, 8\right.$-h) time than MetaSEAL $\left(37^{\circ} \mathrm{C}, 10 \mathrm{~min}\right.$ for initial setting) when MetaSEAL [28] is light-cured. The coronal photoactivation of the sealer, following the manufacturer's instructions, may have prevented the flow of resin sealer [29]. A slow polymerizing sealer can help to relieve shrinkage stress via resin flow. The manufacturer of MetaSeal (Parkell) [28] recommends using a single cone technique with their material because they state that heat will cause the sealer to set up too quickly and cause polymerization shrinkage. Heat transferred during the removal of excess gutta-percha may be the reason for increased leakage and polymerization shrinkage. A recent study by Santos [30] evaluated the sealing ability of AH Plus and a methacrylate-based resin in the long term, and concluded that AH Plus had better sealing ability; this is consistent with our results.

\section{Conclusions}

Results of volumetric determination of dye penetration method were not different when compared with the results of dye extraction method with vacuuming thus our null hypothesis is rejected. Furthermore, because of its easiness conventional dye extraction method may be preferred for future studies, in addition simulating the conditions in the oral cavity.

\section{References}

1. Camps J, Pashley DH (2003) Reliability of the dye penetration studies. J Endod 29: 592-594.

2. Delivanis PD, Chapman KA (1982) Comparison and reliability of techniques for measuring leakage and marginal penetration. Oral Surg Oral Med Oral Pathol Oral Radiol Endod 53: 410-416.

3. Barthel CR, Moshonov J, Shuping G, Orstavik D (1999) Bacterial leakage versus dye leakage in obturated root canals. Int Endod J 32: 370-375.

4. Kim YK, Grandini S, Ames JM, Gu LS, Kim SK, et al. (2010) Critical review on methacrylate resin-based root canal sealers. J Endod 36: 383-389.

5. De-Deus G, Murad C, Paciornik S, Reis CM, Coutinho-Filho T (2008) The effect of the canal-filled area on the bacterial leakage of oval-shaped canals. Int Endod J 41: 183-190.

6. Hashem AA, Hassanien EE (2008) ProRoot MTA, MTA-Angelus and IRM used to repair large furcation perforations: sealability study. J Endod 34: 59-61.

7. Oliver CM, Abbott PV (1991). Entrapped air and its effect on dye penetration of voids. Endod Dent Traumatol 7: 135-138.

8. Spångberg LSW, Acierno TG, Yongbum Cha B (1989) Influence of entrapped air on the accuracy of leakage studies using dye penetration methods. J Endod 15: 548-551.

9. Goldman M, Simmonds S, Rush R (1989) The usefulness of dye penetration studies reexamined. Oral Surg Oral Med Oral Pathol Oral Radiol Endod 67 327-332.

10. Vassiliadis L, Liolios E, Kouvas V, Economides N (1996) Effect of smear layer on coronal microleakage. Oral Surg Oral Med Oral Pathol Oral Radiol Endod 82: $315-320$

11. I Yavuz, A.H Aydın (2005) New method for measurement of surface areas of microleakage at the primary teeth by biomolecule characteristics of methlene blue. Biotechnol \& Biotec Eq 19: 181-187.

12. Yasemin Bulut, Haluk Aydın (2006) A kinetics and thermodynamics study of methlene blue adsorption on wheat shells. Desalination 194: 259-267.

13. Izzet Yavuz, Haluk Aydın (2010) New direction for measurement of microleakage in cariology research. J Int Dent Med Res 3: 19-24.

14. S Brunauer (1942) The adsorption of gases and vapors. Vol 1 Physical Adsorbtion. 1st ed. Princeton University Press 10-20.

15. Akman M, Akman S, Derinbay Ö, Belli S (2010) Evaluation of gaps or voids occurring in roots filled with three different sealers. Eur J Dent 4: 101-109.

16. Pathomvanich S, Edmunds DH (1996) The sealing ability of Thermafil obtutarors assessedby four different microleakage techniques. Int Endod J 29 : 327-334.

17. Schwartz RS (2006) Adhesive density and endodontics: part 2. Bonding in the root canal system: the promise and the problems - a review. J Endod 32: 11251134.

18. Nunes VH, Silva RG, Alfredo E, Sousa-Neto MD, Silva-Sousa YTC (2008) Adhesion of Epiphany and AH Plus sealers to human root dentin treated with different solutions. Braz Dent J 19: 46-50.

19. Hamad HA, Tordik PA, McClanahan SB (2006) Furcation perforation repair comparing gray and white MTA: a dye extraction study. J Endod 32: 337-340.

20. Roda RS, Gutmann JL (1995) Reliability of reduced air pressure methods used to assess the apical seal. Int Endod J 28: 154-162.

21. Wu MK, Kontakiotis EG, Wesselink PR (1998) Decoloration of $1 \%$ methlene blue solution in contact with dental filling materials. J Dent 26: 585-589.

22. Kersten HW, Moorer WR (1989) Particles and molecules in endodontic leakage Int Endod J 22: 118-124.

23. McComb D, Smith DC (1976) Comparison of physical properties of polycarboxylate-based and conventional root canal sealers. J Endod 2: 228235. 
Citation: KAYA S, OZER SY, YAVUZ I, AYDIN H (2011) Comparison of Dye Extraction or Dye Penetration Methods to Quantitatively Determine Microleakage of Three Different Root Canal Sealers. Dentistry 1:105. doi:10.4172/2161-1122.1000105

24. Lee KW, Williams MC, Camps JJ, Pashley DH (2002) Adhesion of endodontic sealers to dentin and gutta-percha. J Endod 28: 684-688.

25. Kaplan AE, Goldberg F, Artaza LP, De Silvio A, Macchi RL (1997) Disintegration of endodontic cements in water. J Endod 23: 439-441.

26. Friedman S, Lost C, Zarrabian M, Trope M (1995) Evaluation of success and failure after endodontic therapy using a glass ionomer cement sealer. J Endod 21: 384-390.

27. Densply AH Plus safety data sheet. URL http://dentsply.com au/ uploadedFiles/1272783856865-2225.pdf [accessed on 17th September 2009].
28. Parkell, MetaSeal safety data sheet. URL http://www.parkell.com/pages/ datasheets/METASEAL/a00509reva508metaseal.pdf [accessed on 19th April 2010]

29. Braga RR, Ferracane JL, Condon JR (2002) Polymerization contraction stress in dual-cure cements and its effect on interfacial integrity of bonded inlays. $J$ Dent 30: 333-340.

30. Santos J, Tjäderhane L, Ferraz C, Zaia A, Alves M, etal. (2010) Long-term sealing ability of resin-based root canal fillings. Int Endod J 43: 455-460. 